\title{
A Monte Carlo Study of Confidence Intervals for the Mean as a Function of Sample Size
}

June 1977

Prepared for the Energy Research and Development Administration under Contract EY-76-C-06-1830 


\section{NOTICE}

This report was prepared as an account of work sponsored by the United States Government. Neither the United States nor the Energy Research and Development Administration, nor any of their employees, nor any of their contractors, subcontractors, or their employees, makes any warranty, express or implied, or assumes any legal liability or responsibility for the accuracy, completeness or usefulness of any information, apparatus, product or process disclosed, or represents that its use would not infringe privately owned rights.

PACIFIC NORTHWEST LABORATORY

operated by

BATTELLE

for the

ENERGY RESEARCH AND DEVELOPMENT ADMINISTRATION

Under Contract EY-76-C-06-1830

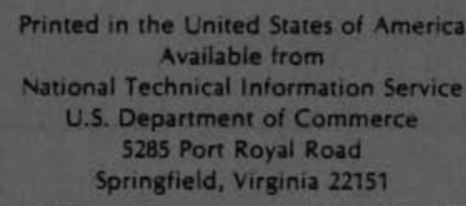

Price: Printed Copy $\$$

$\begin{array}{cc}\text { •Pages } & \text { NTIS } \\ 001-025 & \text { Selling Price } \\ 026-050 & \$ 4.50 \\ 051-075 & 55.00 \\ 076-100 & \$ 5.50 \\ 101-125 & \$ 6.00 \\ 126-150 & \$ 6.50 \\ 151-175 & \$ 7.00 \\ 176-200 & \$ 7.75 \\ 201-225 & \$ 8.50 \\ 226-250 & \$ 8.75 \\ 251-275 & \$ 9.00 \\ 276-300 & \$ 10.00 \\ & \$ 10.25\end{array}$


BNWL -2271

UC -32

A MONTE CARLO STUDY OF CONFIDENCE INTERVALS FOR THE MEAN AS A FUNCTION OF SAMPLE SIZE

by

C. A. Oster

Battelle-Northwest

June 1977

Battelle

Pacific Northwest Laboratories

Richland, WA 99352 
$\checkmark$

,

, 


\section{SUMMARY}

An important parameter in analyzing data by statistical procedures is the number of samples used in the analysis. This report describes a Monte Carlo study of how sample size affects three estimators for the mean and three estimators for the standard deviation of the underlying distribution. Two standard distributions, the Gaussian (normal) and uniform and two others referred to here as the $L$ and $L$-distributions, were used in the study. All four distributions had a mean of zero and a standard deviation of unity.

For each of the four distributions studied the primary result is a probability table for the confidence intervals for an estimate of the mean to contain the true mean of the underlying distribution. A secondary result is a table of the average standard deviation estimates made from all samples of specified size for each distribution. These values may be used to improve the estimates produced by the tested estimators for the standard deviation.

A comparison of the Table A-2 values for the uniform, $L$ and $L$-distributions to the Gaussian distribution indicates that one can expect to obtain confidence intervals which contain the true mean of the underlying distribution with samples of small size. 


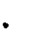


CONTENTS

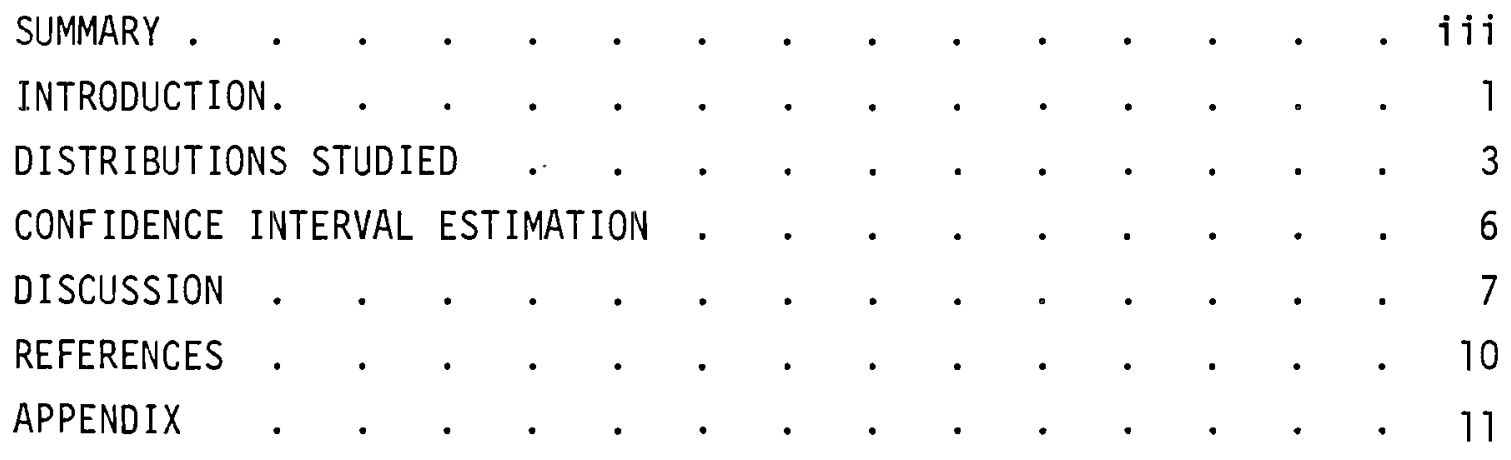



INTRODUCTION

In many statistical studies one is faced with the question of how large must a sample be to adequately represent the process being sampled. Others have addressed this question in similar and different contexts $[1,2]$. To gain insight into the sample size effect, confidence intervals for the mean value were computed from samples randomly selected from several known distributions. The confidence interval estimate generally used is

$$
\hat{0} \pm \varepsilon \hat{\sigma}_{\mu}
$$

where $\hat{\mu}$ is the sample mean based on $N$ observations of the sample, $\varepsilon$ is Student's $t$-value for specified confidence coefficient $1-\alpha(0<\alpha<1)$ and degrees of freedom, and $\hat{\sigma}_{\mu}$ is the estimated standard error of $\hat{\mu}$. If the underlying distribution has a finite second moment, it can be shown that this estimated confidence interval is valid for $N$ sufficiently large regardless of the nonnormality of the data. The question investigated in our study is: How large must $N$ be for the $100(1-\alpha)$ percent confidence interval to be valid for nonnormal data? By "valid" we mean that the probability the estimated confidence interval covers the true mean $\mu$ is $1-\alpha$ even though the data are nonnormal.

Two of the distributions studied in [1] were unimodal but skewed, one to the right and one to the left. The third distribution was bimodal. Here we consider a normal, or Gaussian, and the uniform distributions and two distributions thought to be representative of those which occur when truncating data values to a finite number of digits. We refer to these two as the $\sqcup$ and L-distributions. Each distribution has been constructed so that it has zero mean and unit standard deviation.

This Monte Carlo study consists of randomly selecting a sample of fixed size $N$. Using this sample, estimates of the mean and standard deviation are computed; a sequence of confidence intervals for the mean is constructed; and a count is made of those intervals which includes the actual mean zero. This procedure is repeated many times. For each such interval the ratio of the count to the total number of times the procedure is 
repeated approximates the probability of the interval containing the true mean. The following estimator for the confidence interval is used.

$$
I(\varepsilon)=\hat{\mu}-\varepsilon / \sqrt{N}, \hat{\mu}+\varepsilon / \sqrt{N}
$$

Here we assume $\hat{\partial} \equiv 1$. Hence $I(\varepsilon)$ will be less variable than to be expected if an estimate of $\sigma$ were used. In addition, an average of the sample standard deviations obtained is calculated. Both of these calculations are discussed in detail. 


\section{DISTRIBUTIONS STUDIED}

Four distributions are studied. The Gaussian and uniform distributions are routinely used in practice. The $\sqcup$ and $L$-distributions are models used here to characterize the truncation of numbers so that they can be represented by a finite number of digits. Thus the $\sqcup$-distribution occurs with rounding; the processed number is rounded up or down. There are no other alternatives. The $L$-distribution represents a mix of the uniform and the strict truncation, or chopping-off, of all digits beyond a given point. Each distribution has been adjusted to give zero mean and unit standard deviation. These distributions are explicitly defined in Table 1. The L-distribution has an additional parameter $\gamma$ which has been assigned the value of 0.99 for the study. The values of $\alpha, \beta$ and $h$ then have values of $-0.08693,17.2989$ and 0.00057518 , respectively.

Several methods can be used to estimate the central value and dispersion parameters of the distributions. We consider three methods for estimating each parameter. Estimators for the central value are the arithmetic mean, the median and the mid-range. Estimators for dispersion are the bias corrected root mean square deviation, the mean deviation and the range. The precise definitions of the estimators are shown in Table 2. 


\section{TABLE 1. Distributions Studied}

1. Gaussian

$$
f(x)=\frac{1}{\sqrt{2 \pi}} e^{-\frac{x^{2}}{2}}
$$

2. Uniform

$$
f(x)=\left\{\begin{array}{cc}
\frac{1}{2 \sqrt{3}} & |x| \leq \sqrt{3} \\
0 & |x|>\sqrt{3}
\end{array}\right.
$$

3. Ц-distribution--Double Spike

$$
f(x)=\frac{1}{2}[\delta(-1)+\delta(1)]
$$

where $\delta(\cdot)$ is the Dirac $\delta$-function

4. L-distribution

$$
\begin{aligned}
& f(x)=\gamma \delta(\alpha)+h g(x) \\
& \text { where } g(x)= \begin{cases}1 & \alpha<x \leq \beta \\
0 & \text { elsewhere }\end{cases} \\
& \text { and } 0 \leq \gamma<1 \\
& \alpha=\sqrt{\frac{3(1-\gamma)}{1+3 \gamma}} \\
& \beta=\frac{1+\gamma}{1-\gamma} \sqrt{\frac{3(1-\gamma)}{1+3 \gamma}} \\
& h=\frac{(1-\gamma)^{2}}{2} \sqrt{\frac{1+3 \gamma}{3(1-\gamma)}}
\end{aligned}
$$


TABLE 2. Estimators Used In Study

A. Central Value (Mean)

1. Arithmetic Mean $=\frac{1}{N} \sum_{i=1}^{N} x_{i}$

2. Median

= that $X_{i}$ which has an equal number of observations on each side if $N$ is odd. If $N$ is even, then it is the average of the two middle values.

3. Mid Range $=\frac{1}{2}\left[\min _{i}\left\{x_{i}\right\}+\max _{i}\left\{x_{i}\right\}\right]$

B. Dispersion (Measure of Variability)

1. Standard Deviation $=\sqrt{\frac{\sum_{i=1}^{N}\left[x_{i}-\frac{1}{N} \sum_{i=1}^{N} x_{i}\right]^{2}}{N-1}}$

2. Mean Deviation $=\frac{1}{N} \sum_{i=1}^{N} \mid x_{i}-$ median $\left\{x_{i}\right\} \mid$

3. Range

$$
=\max _{i}\left\{x_{i}\right\}-\min _{i}\left\{x_{i}\right\}
$$




\section{CONFIDENCE INTERVAL ESTIMATION}

The confidence interval for the mean value is estimated by a Monte Carlo procedure. Such a procedure consists of selecting at random a large number of samples from the underlying distribution, then estimating the mean and standard deviation from each sample data set. In this study a distribution is chosen, the sample size fixed at $N \geq 2$, and estimates made for 1000 random samples from the distribution. For each of these samples, estimates of the mean $\hat{\mu}$ and population standard deviation $\hat{\sigma}$ are computed by the appropriate method, which is discussed later. The confidence interval for $\mu$, defined here as a function of $\varepsilon$, is

$$
I(\varepsilon)=[\hat{\mu}-\varepsilon / \sqrt{N}, \hat{\mu}+\varepsilon / \sqrt{N}] .
$$

An array of counters $p_{j}, i=1,2, \ldots, 51$ is defined and initially set to zero. A set of discrete values $\varepsilon_{i}$ is defined by $\varepsilon_{i}=(i-1) / 10, i=1$, $2, \ldots, 51$. Now for any given sample, all counters $p_{j}$ are incremented if $\mu \varepsilon I\left(\varepsilon_{j}\right)$, that is, if the confidence interval $I\left(\varepsilon_{j}\right)$ contains the true mean of the underlying distribution.

After a11 1000 samples have been processed, the probability of including the true mean in a confidence interval $I\left(\varepsilon_{j}\right)$ is estimated by

$$
P\left\{\hat{\mu}-\varepsilon_{i} / \sqrt{N}<\mu<\hat{\mu}+\varepsilon_{j} / \sqrt{N}\right\} \approx p_{j} / 1000 \text {. }
$$

Values of $p_{j} / 1000$ for $i=11,21,31,41$ and 51 are tabulated in the Appendix for the four underlying distributions, using the Table 2 mean estimators for sample sizes $N=2,3,4,5,7,10,25$ and 100 . For any one underlying distribution the 1000 samples of size $\mathrm{N}$ were the same for all estimation methods.

The particular cases run are identified by three indices. The first index $i$ denotes the underlying distribution as defined in Table 1 . The second and third indices denote the method used to estimate the mean and to characterize the variability, respectively, as shown in Table 2. For example, Run 123 denotes a Gaussian distribution; the mean estimator is the median; and the estimator of variability is the range. 


\section{DISCUSSION}

The Appendix contains two tables. Table A-1 lists estimates of the average standard deviation $\hat{\bar{\sigma}}$ obtained by averaging the 1000 sample estimates of $\hat{\bar{\sigma}}$ for size $N$. Table A-2 lists estimates of the probability that a given confidence interval contains the true mean of the underlying distribution. The mean deviation and range are biased estimators of the standard deviation. One check on the entire study can be obtained from [2]. Table 16-4 of that reference contains factors needed to yield unbiased estimates of the standard deviation using the range as the estimator when the underlying distribution is Gaussian. This corresponds to Run $1 j 3$. The corresponding values of $\hat{\bar{\sigma}}$ from this run are listed in Table 3 along with the bias correction factor from [2]. The product of $\hat{\bar{\sigma}}$ and the bias correction factor yields an unbiased estimate for $\sigma$. Column four contains the unbiased estimates for $\sigma$. The agreement is quite good since $\sigma=1$. In fact the reciprocal of the entries in Table A-1 should be approximately the correction factors needed to unbias the standard deviation estimators listed in Table 2.

TABLE 3. Standard Deviation Bias Correction for Runs $1 j 3$

\begin{tabular}{|c|c|c|c|}
\hline $\mathrm{N}$ & $\hat{\bar{\sigma}}$ & $\begin{array}{l}\text { Correction } \\
\text { Factor* }\end{array}$ & $\begin{array}{l}\text { Unbiased } \\
\text { Estimate }\end{array}$ \\
\hline 2 & 1.163 & 0.886 & 1.030 \\
\hline 3 & 1.744 & 0.591 & 1.031 \\
\hline 4 & 2.056 & 0.486 & 0.999 \\
\hline 5 & 2.339 & 0.430 & 1.006 \\
\hline 7 & 2.675 & 0.370 & 0.990 \\
\hline 10 & 3.086 & 0.325 & 1.003 \\
\hline
\end{tabular}

* See Table 16-4 of Reference 2

The $L$ and $L$-distributions produce some perhaps surprising results as listed in Table A-2. In fact these results can be explained as we shall now do. First consider the $\sqcup$-distribution. Examination of Runs $3 j k$ in Table $A-2$ reveals that if the interval is short, e.g., $\varepsilon=1$ or 2 , the true mean will 
not be covered, but if the interval is large, e.g., $\varepsilon>3$, it will be covered. The probability of the entire sample of size $N$ being drawn from one end is $\left(\frac{1}{2}\right)^{N}+\left(\frac{1}{2}\right)^{N}=2^{1-N}$. This quantity is tabulated below for the given values of $\mathrm{N}$ used here.

\begin{tabular}{|c|c|c|}
\hline $\mathrm{N}$ & $2^{1-N}$ & $1-2^{1-N}$ \\
\hline 2 & 0.5 & 0.5000 \\
\hline 3 & 0.25 & 0.7500 \\
\hline 4 & 0.1250 & 0.8750 \\
\hline 5 & 0.0625 & 0.9375 \\
\hline 7 & 0.0156 & 0.9844 \\
\hline 10 & 0.0020 & 0.9980 \\
\hline 25 & $2.98 \times 10^{-8}$ & 1.0000 \\
\hline 100 & $7.89 \times 10^{-31}$ & 1.0000 \\
\hline
\end{tabular}

Should the entire sample come from one end, the central value estimate $\hat{\beta}$ is -1 or +1 and the dispersion estimate is 0 . Thus when $N$ is smal1, there is a good chance that all samples are drawn from the same end of the distribution. The confidence interval $I(\varepsilon)$ has length $2 \varepsilon / \sqrt{N}$ which exceeds 2 for all $\varepsilon>\sqrt{N}$. Any interval centered at an end point and having length greater than 2 will include the true mean. For example if $\mathrm{N}=2$, there is a $50 \%$ chance of selecting both samples from the same end point. In addition, the confidence interval has length $\sqrt{2} \varepsilon$, which are greater than 2 if $\varepsilon>\sqrt{2}=1.414$. Table A-2's values show that 511 samples of size 2 had both values drawn from the same end of the distribution. When this occurs and $\varepsilon=1$, the confidence interval estimate is too short to extend to the origin. All other cases produce interval estimates which span the true mean.

Similarly when $N=3$, the length of $I(\varepsilon)$ is $\varepsilon \sqrt{3}$, which is greater than 2 when $\varepsilon>\frac{2}{3} \sqrt{3}=1.14$. If the mean estimator is the median $(j=2)$, then it will always be -1 or +1 and the true mean will never be included in $I(\varepsilon)$ for $\varepsilon=1$ and will always be included if $\varepsilon>\frac{2}{3} \sqrt{3}$. When using either of the other two estimators for the mean $(j=1$ or 3$)$, there is $25 \%$ chance of the estimate being either -1 or +1 . If the estimate of the mean is -1 or +1 , then again $I(\varepsilon)$ with $\varepsilon=1$ does not span the true mean. But in $75 \%$ of the cases the estimate is close enough (actually the value is $-\frac{1}{3}$, 0 or $\frac{1}{3}$ ) that $I(1)$ 
spans the origin. The values in Table A-2 are both 1isted as 0.800 (recal1 the same set of sample values used for all three cases using $L$-distribution).

Similar analyses can be made of higher values of $N$. For example, if $N=5$ and the mean estimate is -1 or +1 , no interval $I(\varepsilon)$ spans the origin if $\varepsilon \leq \sqrt{5}=2.24$. This explains the jump between $\varepsilon=2$ and $\varepsilon=3$ for Run $32 \mathrm{k}$ in Table A-2. This jump is moved to the right for larger values of $N$ since the confidence interval grows shorter as $\mathrm{N}$ increases.

The L-distribution may be analyzed in a similar manner. The probability of the entire sample of size $N$ being drawn from $\delta(\alpha)$-part of the distribution is $\gamma^{N}$. Values of this quantity are given in the table below $(\gamma=0.99$ in the examples examined here).

\begin{tabular}{|c|c|c|}
\hline$N$ & $\gamma^{N}$ & $1-y^{N}$ \\
\hline 2 & 0.9801 & 0.0199 \\
\hline 3 & 0.9703 & 0.0297 \\
\hline 4 & 0.9606 & 0.0394 \\
\hline 5 & 0.9510 & 0.0490 \\
\hline 7 & 0.9321 & 0.0679 \\
\hline 10 & 0.9044 & 0.0956 \\
\hline 25 & 0.7778 & 0.2222 \\
\hline 100 & 0.3660 & 0.6340 \\
\hline
\end{tabular}

If the entire sample is drawn from $\delta(\alpha)$, then the central value estimators all produce the value $\alpha$, and the standard deviation estimators produce the value 0 . Again the confidence interval estimate has length $2 \varepsilon / \sqrt{N}$ and wi11 span the origin for all $\varepsilon \geq-\alpha \sqrt{\mathrm{N}}=0.08693 \sqrt{\mathrm{N}}$. The values for $\varepsilon 1$ isted in Table A-2 are larger than this lower bound. Hence the origin is nearly always included in the confidence interval.

If the entire sample is from the uniform part of the L-distribution, the expected value is $(\alpha+\beta) / 2=8.606$, hence for $I(\varepsilon)$ to include the true mean requires a value of $\varepsilon$ in excess of $8.606 \sqrt{N}$, which for $N=2$ is greater than 12. Such large values of $\varepsilon$ are not included in Table A-2. 


\section{REFERENCES}

1. James P. Barrett and Leland Goldsmith, "When is n Sufficiently Large?" The American Statistician, Vol. 30, No. 2, pp. 67-70, May 1976.

2. Wilfrid J. Dixon and Frank J. Massey, Jr., Introduction to Statistical Analysis, pp. 238-246, McGraw-Hil1 Book Co., Inc., New York, 1951. 
APPENDIX

SELECTED VALUES FROM THE MONTE CARLO OUTPUT 
TABLE A-1. Average Estimate of Dispersion

\begin{tabular}{|c|c|c|c|c|c|c|c|c|}
\hline $\operatorname{un} / \mathrm{N}$ & 2 & 3 & 4 & 5 & 7 & 10 & 25 & 100 \\
\hline $\begin{array}{l}1 j 1 \\
1 j 2 \\
1 j 33\end{array}$ & $\begin{array}{l}0.822 \\
0.581 \\
1.163\end{array}$ & & & & & & & \\
\hline $\begin{array}{l}2 j 1 \\
2 j 2 \\
2 j 3\end{array}$ & 572 & $\begin{array}{l}0.932 \\
0.897 \\
1.772\end{array}$ & & & & & & \\
\hline $\begin{array}{l}3 \mathrm{j} 1 \\
3 \mathrm{j} 2 \\
3 \mathrm{j} 3\end{array}$ & $\begin{array}{l}692 \\
489 \\
978\end{array}$ & & & & & & & \\
\hline $\begin{array}{l}4 j 1 \\
4 j 2 \\
4 j 3\end{array}$ & $\begin{array}{l}0.293 \\
0.207 \\
0.415\end{array}$ & $\begin{array}{l}0.315 \\
0.182 \\
0.545\end{array}$ & $\begin{array}{l}0.362 \\
0.185 \\
0.727\end{array}$ & $\begin{array}{l}0.353 \\
0.159 \\
0.790\end{array}$ & & & & \\
\hline
\end{tabular}


TABLE A-2. Estimates of the Probability that a Given Confidence Interval I $(\varepsilon)$ Contains the True Mean as a Function of Sample Size $\mathrm{N}$

$N=2$

\begin{tabular}{|c|c|c|c|c|c|}
\hline Run $\backslash \varepsilon$ & 1 & 2 & 3 & 4 & 5 \\
\hline $\begin{array}{l}11 k \\
12 k \\
13 k\end{array}$ & $\begin{array}{l}0.659 \\
0.659 \\
0.659\end{array}$ & $\begin{array}{l}0.954 \\
0.954 \\
0.954\end{array}$ & $\begin{array}{l}0.999 \\
0.999 \\
0.999\end{array}$ & $\begin{array}{l}1.000 \\
1.000 \\
1.000\end{array}$ & $\begin{array}{l}1.000 \\
1.000 \\
1.000\end{array}$ \\
\hline $\begin{array}{l}21 k \\
22 k \\
23 k\end{array}$ & $\begin{array}{l}0.662 \\
0.662 \\
0.662\end{array}$ & $\begin{array}{l}0.967 \\
0.967 \\
0.967\end{array}$ & $\begin{array}{l}1.000 \\
1.000 \\
1.000\end{array}$ & $\begin{array}{l}1.000 \\
1.000 \\
1.000\end{array}$ & $\begin{array}{l}1.000 \\
1.000 \\
1.000\end{array}$ \\
\hline $\begin{array}{l}31 k \\
32 k \\
33 k\end{array}$ & $\begin{array}{l}0.489 \\
0.489 \\
0.489\end{array}$ & $\begin{array}{l}1.000 \\
1.000 \\
1.000\end{array}$ & $\begin{array}{l}1.000 \\
1.000 \\
1.000\end{array}$ & $\begin{array}{l}1.000 \\
1.000 \\
1.000\end{array}$ & $\begin{array}{l}1.000 \\
1.000 \\
1.000\end{array}$ \\
\hline $\begin{array}{l}41 k \\
42 k \\
43 k\end{array}$ & $\begin{array}{l}0.976 \\
0.976 \\
0.976\end{array}$ & $\begin{array}{l}0.979 \\
0.979 \\
0.979\end{array}$ & $\begin{array}{l}0.979 \\
0.979 \\
0.979\end{array}$ & $\begin{array}{l}0.980 \\
0.980 \\
0.980\end{array}$ & $\begin{array}{l}0.980 \\
0.980 \\
0.980\end{array}$ \\
\hline
\end{tabular}

$N=3$

$\underline{\text { Run } \backslash \varepsilon}$

$11 \mathrm{k}$

$12 k$

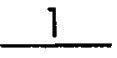

2
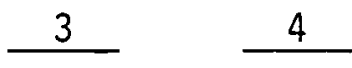

5

$13 k$

0.693

0.970

0.346

0.657

0.999

1.000

0.967

1.000

0.662

0.959

0.999

1.000

0.995

$21 \mathrm{k}$

0.710

0.968

0.262

0.744

0.586

1.000

1.000

1.000

$23 \mathrm{k}$

0.970

1.000

1.000

1.000

1.000

1.000

$31 \mathrm{k}$

$32 k$

0.800

1.000

1.000

1.000

1.000

0.800

1.000

1.000

1.000

1.000

1.000

1.000

1.000

$41 \mathrm{k}$

0.970

0.971

1.000

1.000

0.973

1.000

0.974

1.000

0.972

0.978

0.970

0.971

1.000

0.973 
TABLE 2. (contd)

$N=4$

\begin{tabular}{|c|c|c|c|c|c|}
\hline Run $\backslash \varepsilon$ & 1 & 2 & 3 & 4 & 5 \\
\hline $\begin{array}{l}11 k \\
12 k \\
13 k\end{array}$ & $\begin{array}{l}0.665 \\
0.633 \\
0.622\end{array}$ & $\begin{array}{l}0.950 \\
0.924 \\
0.926\end{array}$ & $\begin{array}{l}1.000 \\
0.990 \\
0.997\end{array}$ & $\begin{array}{l}1.000 \\
1.000 \\
1.000\end{array}$ & $\begin{array}{l}1.000 \\
1.000 \\
1.000\end{array}$ \\
\hline $\begin{array}{l}21 k \\
22 k \\
23 k\end{array}$ & $\begin{array}{l}0.642 \\
0.543 \\
0.724\end{array}$ & $\begin{array}{l}0.946 \\
0.866 \\
0.963\end{array}$ & $\begin{array}{l}1.000 \\
0.997 \\
1.000\end{array}$ & $\begin{array}{l}1.000 \\
1.000 \\
1.000\end{array}$ & $\begin{array}{l}1.000 \\
1.000 \\
1.000\end{array}$ \\
\hline $\begin{array}{l}31 k \\
32 k \\
33 k\end{array}$ & $\begin{array}{l}0.859 \\
0.358 \\
0.859\end{array}$ & $\begin{array}{l}1.000 \\
1.000 \\
1.000\end{array}$ & $\begin{array}{l}1.000 \\
1.000 \\
1.000\end{array}$ & $\begin{array}{l}1.000 \\
1.000 \\
1.000\end{array}$ & $\begin{array}{l}1.000 \\
1.000 \\
1.000\end{array}$ \\
\hline $\begin{array}{l}41 k \\
42 k \\
43 k\end{array}$ & $\begin{array}{l}0.958 \\
0.999 \\
0.957\end{array}$ & $\begin{array}{l}0.959 \\
0.999 \\
0.958\end{array}$ & $\begin{array}{l}0.960 \\
0.999 \\
0.959\end{array}$ & $\begin{array}{l}0.964 \\
0.999 \\
0.959\end{array}$ & $\begin{array}{l}0.968 \\
0.999 \\
0.960\end{array}$ \\
\hline
\end{tabular}

$N=5$

\begin{tabular}{|c|c|c|c|c|c|}
\hline Run\} \backslash \varepsilon $&{1} &{2} &{3} &{4} &{5} \\
{\hline \begin{array}{l}11 k \\
12 k \\
13 k\end{array}} &{\begin{array}{l}0.701 \\
0.441 \\
0.608\end{array}} &{\begin{array}{l}0.963 \\
0.774 \\
0.920\end{array}} &{\begin{array}{l}0.997 \\
0.936 \\
0.995\end{array}} &{\begin{array}{l}1.000 \\
0.984 \\
1.000\end{array}} &{\begin{array}{l}1.000 \\
0.999 \\
1.000\end{array}} \\
{\hline \begin{array}{l}21 k \\
22 k \\
23 k\end{array}} &{\begin{array}{l}0.707 \\
0.339 \\
0.793\end{array}} &{\begin{array}{l}0.969 \\
0.633 \\
0.980\end{array}} &{\begin{array}{l}1.000 \\
0.891 \\
0.999\end{array}} &{\begin{array}{l}1.000 \\
1.000 \\
1.000\end{array}} &{\begin{array}{l}1.000 \\
1.000 \\
1.000\end{array}} \\
{\hline \begin{array}{l}31 k \\
32 k \\
33 k\end{array}} &{\begin{array}{l}0.665 \\
0 \\
0.956\end{array}} &{\begin{array}{l}0.956 \\
0 \\
0.956\end{array}} &{\begin{array}{l}1.000 \\
1.000 \\
1.000\end{array}} &{\begin{array}{l}1.000 \\
1.000 \\
1.000\end{array}} &{\begin{array}{l}1.000 \\
1.000 \\
1.000\end{array}} \\
{\hline \begin{array}{l}41 k \\
42 k \\
43 k\end{array}} &{\begin{array}{l}0.953 \\
1.000 \\
0.950\end{array}} &{\begin{array}{l}0.958 \\
1.000 \\
0.951\end{array}} &{\begin{array}{l}0.963 \\
1.000 \\
0.953\end{array}} &{\begin{array}{l}0.964 \\
1.000 \\
0.957\end{array}} &{\begin{array}{l}0.968 \\
1.000 \\
0.958\end{array}} \\
$\hline
\end{tabular}


TABLE 2. (contd)

$N=7$

\begin{tabular}{|c|c|c|c|c|c|}
\hline Run $\backslash \varepsilon$ & 1 & 2 & 3 & 4 & 5 \\
\hline $\begin{array}{l}11 k \\
12 k \\
13 k\end{array}$ & $\begin{array}{l}0.694 \\
0.456 \\
0.585\end{array}$ & $\begin{array}{l}0.957 \\
0.805 \\
0.894\end{array}$ & $\begin{array}{l}0.996 \\
0.953 \\
0.977\end{array}$ & $\begin{array}{l}1.000 \\
0.992 \\
0.999\end{array}$ & $\begin{array}{l}1.000 \\
0.999 \\
1.000\end{array}$ \\
\hline $\begin{array}{l}21 k \\
22 k \\
23 k\end{array}$ & $\begin{array}{l}0.678 \\
0.333 \\
0.834\end{array}$ & $\begin{array}{l}0.958 \\
0.651 \\
0.986\end{array}$ & $\begin{array}{l}1.000 \\
0.903 \\
1.000\end{array}$ & $\begin{array}{l}1.000 \\
0.995 \\
1.000\end{array}$ & $\begin{array}{l}1.000 \\
1.000 \\
1.000\end{array}$ \\
\hline $\begin{array}{l}31 k \\
32 k \\
33 k\end{array}$ & $\begin{array}{l}0.548 \\
0 \\
0.988\end{array}$ & $\begin{array}{l}0.988 \\
0 \\
0.988\end{array}$ & $\begin{array}{l}1.000 \\
1.000 \\
1.000\end{array}$ & $\begin{array}{l}1.000 \\
1.000 \\
1.000\end{array}$ & $\begin{array}{l}1.000 \\
1.000 \\
1.000\end{array}$ \\
\hline $\begin{array}{l}41 k \\
42 k \\
43 k\end{array}$ & $\begin{array}{l}0.927 \\
1.000 \\
0.923\end{array}$ & $\begin{array}{l}0.935 \\
1.000 \\
0.925\end{array}$ & $\begin{array}{l}0.940 \\
1.000 \\
0.927\end{array}$ & $\begin{array}{l}0.946 \\
1.000 \\
0.927\end{array}$ & $\begin{array}{l}0.952 \\
1.000 \\
0.930\end{array}$ \\
\hline
\end{tabular}

$N=10$

Run\} \varepsilon
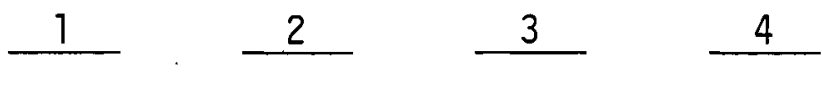

5

$11 \mathrm{k} \cdot 0.665$

0.954

0.999

1.000

1.000

$12 \mathrm{k} \quad 0.598$

0.917

0.992

0.999

1.000

$13 k$

0.527

0.839

0.968

0.996

1.000

$21 \mathrm{k}$

0.668

0.949

0.999

1.000

1.000

$22 \mathrm{k}$

0.454

0.800

0.958

0.999

1.000

1.000

$23 k$

0.874

0.988

1.000

1.000

1.000

$31 \mathrm{k}$

0.652

0.982

0.998

0.248

0.248

1.000

1.000

$33 k$

0.998

0.998

0.988

1.000

1.000

$41 \mathrm{k}$

0.921

$42 k$

0.927
1.000
0.915

0.937

0.946

1.000

0.952

1.000

0.918

1.000

0.913

0.917

0.920 
TABLE 2. (contd)

$N=25$

\begin{tabular}{|c|c|c|c|c|c|}
\hline Run $\backslash \varepsilon$ & 1 & 2 & 3 & 4 & 5 \\
\hline $\begin{array}{l}11 \mathrm{k} \\
12 \mathrm{k} \\
13 \mathrm{k}\end{array}$ & $\begin{array}{l}0.692 \\
0.566 \\
0.415\end{array}$ & $\begin{array}{l}0.959 \\
0.878 \\
0.718\end{array}$ & $\begin{array}{l}0.998 \\
0.983 \\
0.898\end{array}$ & $\begin{array}{l}1.000 \\
0.997 \\
0.954\end{array}$ & $\begin{array}{l}1.000 \\
1.000 \\
0.991\end{array}$ \\
\hline $\begin{array}{l}21 k \\
22 k \\
23 k\end{array}$ & $\begin{array}{l}0.691 \\
0.416 \\
0.953\end{array}$ & $\begin{array}{l}0.960 \\
0.726 \\
1.000\end{array}$ & $\begin{array}{l}0.995 \\
0.901 \\
1.000\end{array}$ & $\begin{array}{l}1.000 \\
0.977 \\
1.000\end{array}$ & $\begin{array}{l}1.000 \\
0.996 \\
1.000\end{array}$ \\
\hline $\begin{array}{l}31 k \\
32 k \\
33 k\end{array}$ & $\begin{array}{l}0.778 \\
0 \\
1.000\end{array}$ & $\begin{array}{l}0.959 \\
0 \\
1.000\end{array}$ & $\begin{array}{l}0.999 \\
0 \\
1.000\end{array}$ & $\begin{array}{l}1.000 \\
0 \\
1.000\end{array}$ & $\begin{array}{l}1.000 \\
1.000 \\
1.000\end{array}$ \\
\hline $\begin{array}{l}41 k \\
42 k \\
43 k\end{array}$ & $\begin{array}{l}0.845 \\
1.000 \\
0.811\end{array}$ & $\begin{array}{l}0.871 \\
1.000 \\
0.812\end{array}$ & $\begin{array}{l}0.903 \\
1.000 \\
0.815\end{array}$ & $\begin{array}{l}0.926 \\
1.000 \\
0.816\end{array}$ & $\begin{array}{l}0.954 \\
1.000 \\
0.819\end{array}$ \\
\hline
\end{tabular}

$N=100$

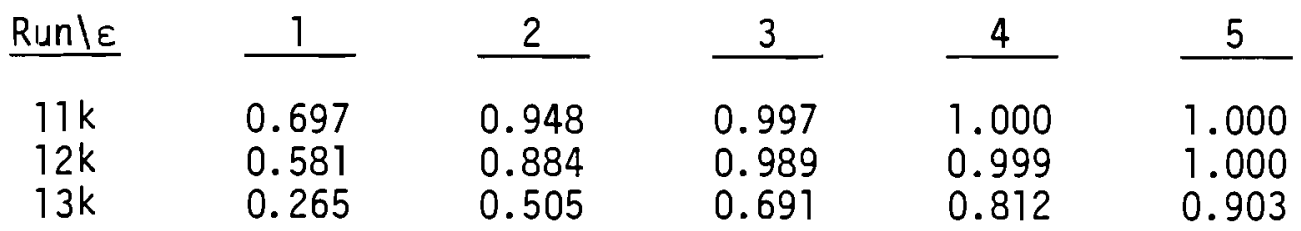

$\begin{array}{llllll}21 k & 0.678 & 0.961 & 0.998 & 1.000 & 1.000 \\ 22 k & 0.434 & 0.753 & 0.923 & 0.988 & 0.998 \\ 23 k & 0.996 & 1.000 & 1.000 & 1.000 & 1.000 \\ 31 k & 0.722 & 0.965 & 1.000 & 1.000 & 1.000 \\ 32 k & 0.077 & 0.077 & 0.077 & 0.077 & 0.077 \\ 33 k & 1.000 & 1.000 & 1.000 & 1.000 & 1.000 \\ 41 k & 0.585 & 0.739 & 0.870 & 0.918 & 0.957 \\ 42 k & 1.000 & 1.000 & 1.000 & 1.000 & 1.000 \\ 43 k & 0.363 & 0.365 & 0.369 & 0.370 & 0.372\end{array}$


DISTRIBUTION

No. of

Copies

OFFSITE

1 ERDA Chicago Patent Group 9800 So. Cass Avenue

Argonne, OL 60439

A. A. Churm

Division of Mathematics and Computers Energy Research and Development Administration Washington, D.C. 20545

27 ERDA Technical Information Center

W. R. Burrus

Mini-Max Services, Inc. 312 W. Broadway Lenoir City, TN 37771

ERDA

H. E. Ransom
No. of

Copies

\section{OINSITE}

9 Battelle-Northwest

C. A. Oster (5)

D. S. Trent

Technical Information

7 Hanford Engineering Development Laboratory

D. G. Doran

R. Gold

J. J. Laidler/H. H. Yoshikawa

E. P. Lippincott

W. N. McElroy

J. 0. Schiffgens

R. C. Simons 
. 